\title{
Analyzing the Risk of Well Plug Failure after Abandonment
}

\author{
M. Mainguy*, P. Longuemare, A. Audibert** and E. Lécolier \\ 1 Institut français du pétrole, IFP, 1-4, avenue de Bois-Préau, 92852 Rueil-Malmaison Cedex - France \\ email: marc.mainguy@total.com - pascal.longuemare@ifp.fr - annie.audibert-hayet@total.com - eric.lecolier@ifp.fr \\ * Present address: CSTJF, avenue Larribau, 64018 Pau Cedex France \\ ** Present address: TOTAL, place de la Coupole, 92400 La Défense France
}

Resumé - Analyse du risque de rupture de la cimentation des puits après leur abandon - À la fin de leur exploitation, les puits de pétrole ou de gaz doivent être obturés au moyen d'une barrière solide consolidée. La procédure d'obturation doit assurer l'efficacité de l'étanchéité du puits afin d'éviter, d'une part, tout risque environnemental induit par une migration des fluides du gisement vers la surface ou vers un aquifère et, d'autre part, des interventions onéreuses sur le système d'obturation. Les travaux publiés dans ce domaine portent sur l'analyse du comportement de la barrière solide consolidée (bouchon de ciment) soumise à un changement local de la pression ou de la température mais ne considèrent pas l'effet des variations de pression, température et de contraintes autour du puits en phase d'exploitation et durant le retour progressif à l'équilibre suite à la fin de l'exploitation. Dans ce travail, la perturbation des contraintes en place est estimée en utilisant le couplage entre un simulateur de réservoir et un simulateur de géomécanique. Ces simulations fournissent l'évolution des variables thermiques, hydrauliques et mécaniques dans les roches de couverture qui constituent le lieu de positionnement des bouchons d'obturation. Les variations de contraintes sont ensuite utilisées comme données d'entrée d'un modèle mécanique pour définir le chargement dans le temps subi par un puits injecteur à l'issue de l'exploitation. Ce modèle permet de calculer localement l'évolution des sollicitations au niveau du bouchon de ciment. Les résultats obtenus avec le modèle mécanique au niveau du puits pour un ciment conventionnel de type Classe $\mathrm{G}$ montrent que le risque principal est la rupture en traction. Il est ainsi observé que les matériaux d'étanchéité relativement déformables ou initialement pré-contraints apparaissent comme les mieux adaptés face à l'évolution des conditions en fond de puits qui peuvent se produire après la fin d'exploitation du champ.

Abstract - Analyzing the risk of well plug failure after abandonment - All oil and gas wells will have to be plugged and abandoned at some time. The plugging and abandonment procedure must provide an effective isolation of the well fluids all along the well to reduce environmental risks of contamination and prevent from costly remedial jobs. Previous works have analyzed the plug behavior when submitted to local pressure or thermal changes but no work has looked to the effects of external pressure, thermal and stress changes resulting from a global equilibrium restoration in a hydrocarbon reservoir once production has stopped. This work estimates those changes after abandonment on a reservoir field case using a reservoir simulator in conjunction with a geomechanical simulator. Such simulations provide the pressure and thermal changes and the maximum effective stress changes in the reservoir cap rock where critical plugs are put in place for 
isolating the production intervals. These changes are used as loads in a well bore stress model that explicitly models an injector well and predict stress rearrangements in the plug after abandonment. Results obtained with the well bore stress model for a conventional class G cement plug show that the main risk of failure is tensile failure because of the low tensile strength of the cement. Actually, soft sealing materials or initially pre-stressed plug appears to be more adapted to the downhole conditions changes that may occurs after well plugging and abandonment.

\section{INTRODUCTION AND METHODOLOGY}

In the oil and gas industry, most of oil and gas wells drilled for exploration and field production will have to be plugged and abandoned at one time. The well plugging and abandonment procedure aims at preventing fluid leakages along the well so that all the fluids will remain permanently confined in the separate strata containing them before plugging. To do so, several critical intervals of the well must be plugged from the bottom hole to the surface with a particular attention being paid to the production interval (Kelm and Faul, 1999). The sealant material is often cement-based materials for oil and gas wells but bentonite clay is also used for sealing water wells (Calvert and Smith, 1994). For oil and gas wells, the cement setting process is of high concern and can fail because of fluid instability at the interface between the cement slurry and the drilling fluid below the slurry (Crawshaw and Frigaard, 1999). Moreover, even when the cement is properly placed and initially provides an effective hydraulic seal for the reservoir fluids, downhole condition changes after well plugging and abandonment may induce damage to the zonal isolation and lead to fluids leakage.

Because of environmental and cost concerns, operating companies have to pay a large attention to the plugging and abandonment procedures in order to ensure a "successful abandonment" of their wells. Improperly abandoned wells can become a significant threat to groundwater quality and marine ecosystems. Furthermore, the cost of a remedial job to prevent from well leakage could be dramatic for offshore wells. Consequently, plugging and abandonment operations require a careful attention and to adapt the sealant material to the well downhole conditions. The choice of the best sealing material used for well plugging is not obvious and operating companies work on new cement formulations with high performance ensuring zonal isolation during the entire life of the well. Actually, high compressive cements are not always the best solution and the mechanical properties of the sealing material must be adapted to the well downhole condition changes after permanent plugging.

From the mechanical point of view, the plug sealing capacity loss is related to cement failure or cement-rock de-bonding. Several authors have analyzed the risk of the cement sheath failure or de-bonding during the well completion and production phases (see e.g. Thiercelin et al. 1997, Bosma et al. 1999, Philippacopoulos and Berndt 2001, Ravi et al. 2002) but less work has been concerned with cement plug behavior after abandonment. Akgün and Daemen (1999) have analytically and numerically analyzed the plug behavior when submitted to an axial load due to water, drilling mud, gas, or backfill pressures. These authors provide recommendations on the plug length to radius ratio to reduce tensile stress in the plug. Bosma etal. (2000) numerically analyzed the thermal expansion of a rubber-based plug that has been installed in bottom-hole condition after cooling the well. The plug thermal expansion ensures an efficient sealing of the well, but, if not controlled, may lead to its self-destruction or well damage. Nevertheless, the previous works assume no pressure, temperature, and stress changes at the plug-rock location after plug setting, which may result from external conditions to the well. This assumption may not hold for plugged wells located in a field that continues to produce or for plugged wells located in a field for which pressure, thermal, and stress state are not in equilibrium at the beginning of abandonment. This is for instance the case for salt cavern abandonment where the salt creep and the brine thermal expansion can lead to pressure build-up after cavern abandonment (see e.g. Bérest et al., 2001).

If it is possible to evaluate, by different tests or measurements, the pressure, thermal and stress changes during the reservoir production, we have no idea of those changes around reservoir wells after reservoir abandonment. Because it seems difficult to measure those changes after abandonment, this work aims first at forecasting such changes on a realistic field case using reservoir and geomechanical models. The second objective of this work is to analyze the plug behavior when submitted to the downhole condition changes resulting from reservoir abandonment. This will make possible to analyze the plug behavior during abandonment and therefore to see if conventional cement materials can withstand the load resulting from reservoir equilibrium restoration after abandonment. In order to reach these goals, a new multi-scale approach has been developed. 
This multi-scale approach is based on the successive use of three distinct models at different scales as sketched on Figure 1. The scales of the reservoir and geomechanical models are respectively of 1 kilometer and 10 kilometers, whereas the scale of the well bore stress model used for the local analysis is of ten meters. First, a reservoir model is built to simulate the thermal and hydraulic changes during the reservoir production. Then, the reservoir simulation is extended over several periods of time until pressure and thermal restorations occur in the reservoir. This extension in time of the reservoir model forms the reservoir model for abandonment. Second, a geomechanical model is built in association with the reservoir model. This model is an enlargement of the reservoir domain with constitutive laws affected to the different rocks. The geomechanical model receives the thermal and pressure loads from the reservoir model, making possible to forecast the stress history in the reservoir during production and abandonment. Then, when selecting the geomechanical cells where the reservoir wells are located, it is possible to derive the loads (boundary conditions) that apply to the plugged wells during abandonment. Section 2 of this paper presents the results of the reservoir and geomechanical models and the maximum loads that apply to a reservoir cell where a water injector is located (combination of hydraulic and thermal loads due to cold water injection). Third, a local well bore stress model is built (see Section 3) to evaluate how the loads resulting from reservoir abandonment (pore pressure and temperature restoration) can affect the long term plug behavior. Finally, Sections 4 and 5 use the local well bore stress model to analyze the long term behavior of a standard class $G$ cement plug and the influence of the material thermo-elastic properties on the mechanical integrity of the plug.

\section{DOWNWHOLE CHANGES AFTER RESERVOIR ABANDONMENT}

Reservoir production induces down-hole condition changes such as pressure, thermal and total stress changes. Those changes will occur after the end of reservoir production and well abandonment until an equilibrium is reach at down-hole conditions. However, down-hole condition changes that occur after well plugging may lead to a reduction of the plug sealing capacity because of plug failure or cement-rock debonding. Therefore, it is of high concern to estimate the pressure, thermal and stress changes that will develop in the reservoir after abandonment. Such changes are case dependent and have been estimated using coupled reservoir-geomechanics simulations on a reservoir case study built from real field data (see Mainguy et al., 2005).

Figure 2 displays the well pattern of the reservoir model used by Mainguy et al. (2005) for simulating reservoir production and abandonment. The reservoir model gives the pressure and thermal changes during 20 years of production and the reservoir simulation has been extended over 400 years to analyze the pressure and thermal restorations after the end of production. Reservoir production leads to a high pressure drop in the reservoir during the first 3 years of production followed with Enhanced Oil Recovery due to cold water injection. The pressure decrease is slightly uniform in the reservoir whereas the thermal decrease is mainly located around water injectors. After abandonment, reservoir re-pressurization is due to an active aquifer located beneath the reservoir. We assume a partial re-pressurization of the reservoir compared to the initial over-pressurized state and a full recovery of initial temperature. The reservoir re-pressurization is achieved after 130 years of abandonment whereas the thermal recovery approximately takes 400 years.

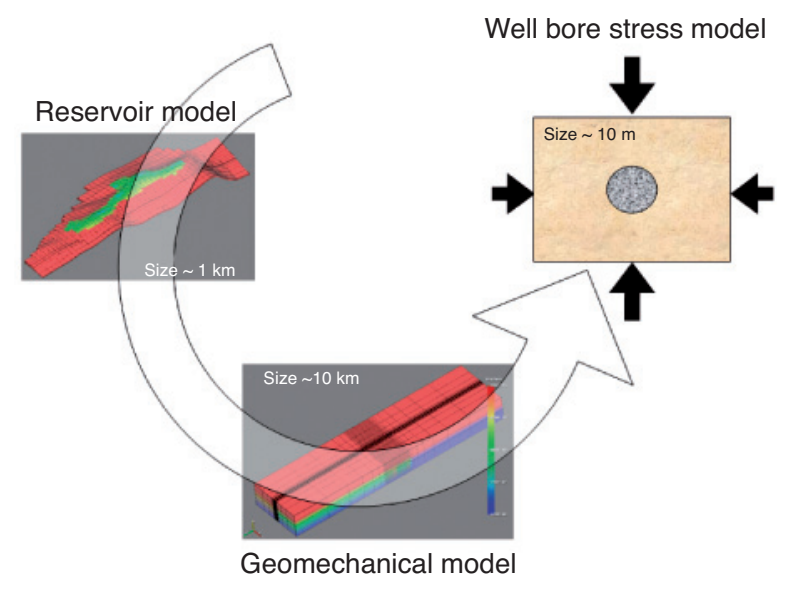

Figure 1

Multiscale approach.

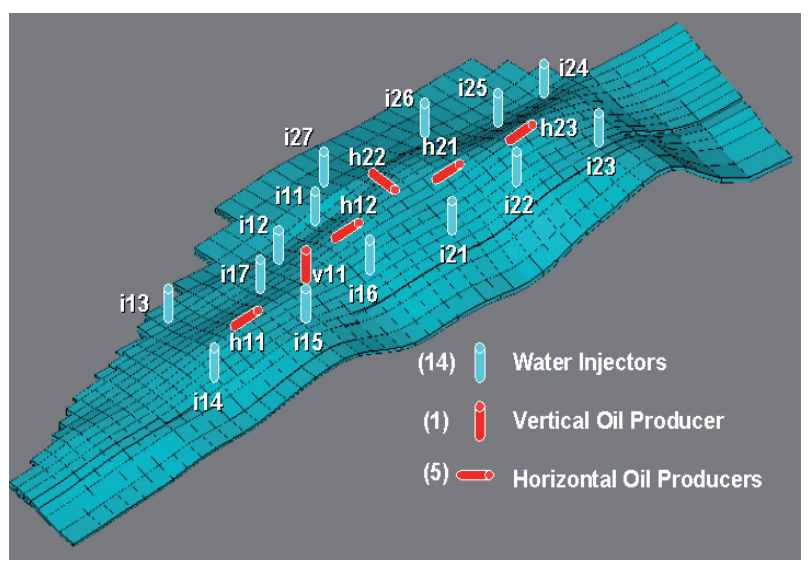

Figure 2

Well distribution of the thermal and fluid flow model. 
Besides, reservoir seal is generally not included in reservoir models. However, operators recommend settling at least one plug over the reservoir in the reservoir cap. The reservoir model is made of 3 reservoir layers and 2 cap rock layers.

The fluid flow and thermal model do not provide any information on the mechanical behavior of the field during production and abandonment. Therefore, this model has been coupled with a stress simulator to predict stress changes during reservoir production and after abandonment. The model not only includes the reservoir and cap rock but also its containment (over-burden, flanks and base rock as displayed on Fig. 3). The model is composed of seven different regions, called rock-zone (RZ), each RZ having its own yield criterion and mechanical properties. From the surface to the base, the rock-zones are overburden 1 (RZ 1): overburden 2 (RZ 2); cap rock (RZ 3 composed of 2 layers); reservoir layer 1 (RZ 4); reservoir layer 2 (RZ 5); reservoir layer 3 (RZ 6); reservoir flanks and base (RZ 7). Region thicknesses are given by Figure 3. Flanks have been modelled over a lateral extension equal to three times the one of the reservoir to provide a representative description of the reservoir containment.

All RZ are isotropic materials. RZ 3 to 6 are modelled as porous media and their mechanical properties are defined with regard to their petrophysical properties defined in the fluid flow model: cap-rock RZ3 is shale, RZ4 is identified as an Adamswiller sandstone, RZ5 is identified as a Berea sandstone and RZ6 is identified as a Darley Dale sandstone. The materials of the remaining $\mathrm{RZ}$ are non-porous materials. Table 1 gives the elastic properties of all RZ ( $E=$ Young's modulus, $v=$ Poisson's ratio and $b=$ Biot's coefficient). RZ 3 to 6 have the same thermal expansion coefficient that is equal to $1.62 \cdot 10^{-5 \circ} \mathrm{C}^{-1}$. RZ 3 to 6 are elastoplastic materials. RZ 3 is supposed to be ideally plastic and is modelled with a Mohr-Coulomb yield criterion (cohesion $=30 \mathrm{MPa}$, friction angle $=20$ degrees and dilatancy angle $=5$ degrees). The behaviour of reservoir RZ (i.e. RZ4, RZ5 and RZ6) is simulated with a modified Cam-Clay model (slope of the critical state line $=1$, consolidation stress $=36 \mathrm{MPa}$, and hardening parameter $=10($ RZ4), $15($ RZ5), $20($ RZ6) $)$.

TABLE 1

Rock-zone elastic properties

\begin{tabular}{l|c|c|c|c|c|c|c}
\hline Rock-zone & RZ1 & RZ2 & RZ3 & RZ4 & RZ5 & RZ6 & RZ7 \\
\hline E (GPa) & 8 & 15 & 10 & 8 & 9 & 10 & 20 \\
\hline$v(-)$ & 0.3 & 0.2 & 0.3 & 0.1 & 0.15 & 0.2 & 0.25 \\
\hline$b(-)$ & - & - & 0.6 & 1 & 1 & 1 & - \\
\hline
\end{tabular}

The stress simulations show that the reservoir behavior is first characterized by reservoir compaction due to oil production. The vertical displacement is about $70 \mathrm{~cm}$ at the crest of the reservoir after 20 years of production. After the end of

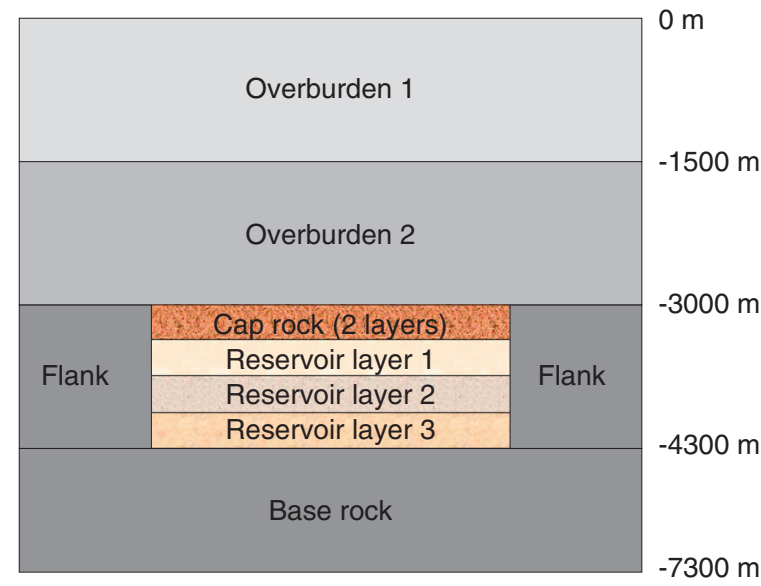

Figure 3

Sketch of the domains.

production, the reservoir re-pressurization leads to a progressive decompaction of the reservoir with a final permanent vertical displacement of about $50 \mathrm{~cm}$ remaining in the first reservoir layer. Because the reservoir unloading during the abandonment phase is associated with elastic strain, the permanent displacement remaining at the end of the abandonment is associated with plastic strain during the production period and to the difference between the initial and final pressures in the reservoir (partial re-pressurization).

One well is chosen in order to closely analyze the pressure, thermal and stress changes resulting from reservoir abandonment. The well under consideration is the vertical injector well I21 (see Fig. 2). Figures 4 and 5 display the temperature and pressure evolutions with time in the 3 cells of the reservoir layers and the 2 cells of the cap rock layers crossed by vertical injector I21. A large thermal decrease from $111^{\circ} \mathrm{C}$ to $42^{\circ} \mathrm{C}$ occurs during production in reservoir layers 1 and 2 where cold water is injected. In comparison, the cap rock layer in contact with the reservoir undergoes a maximal thermal decrease of $27^{\circ} \mathrm{C}$ whereas the thermal decrease is minimal in the first cap rock layer and the third reservoir layer (about $20^{\circ} \mathrm{C}$ ). Note that the cooling of these two layers continues after the end of injection because of heat exchanges with cooler cells. After 50 years, the temperatures of all layers are similar with a small difference of $5^{\circ} \mathrm{C}$ max and all values slowly tend toward the initial value of $111^{\circ} \mathrm{C}$. The three reservoir layers behave similarly during production and abandonment: the pressure decrease of $25 \mathrm{MPa}$ during production is followed by a pressure increase up to $35.5 \mathrm{MPa}$ during abandonment. The pressure drop of the cap rock layers is also significant (20 MPa for the layer in contact with the reservoir and $12 \mathrm{MPa}$ for the other one). The pressure 


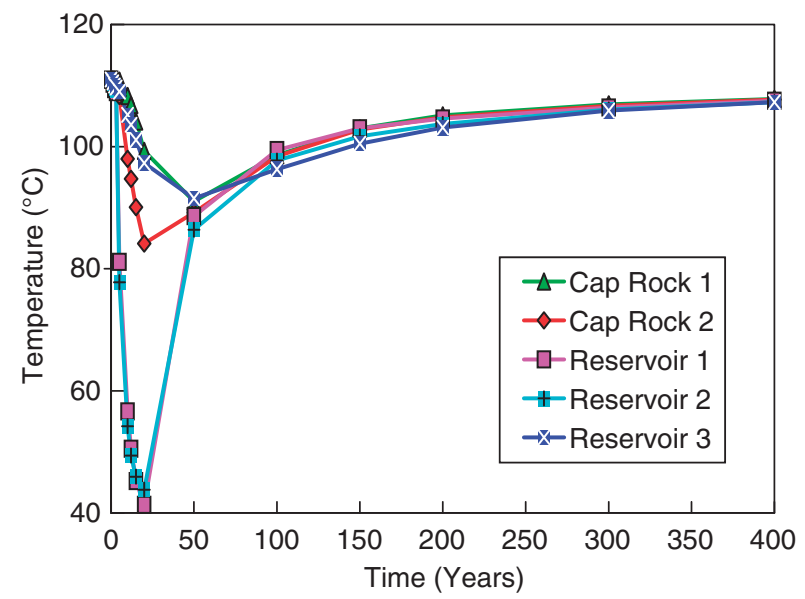

Figure 4

Evolution with time of temperature in reservoir and cap rock for cells crossed by well I21.

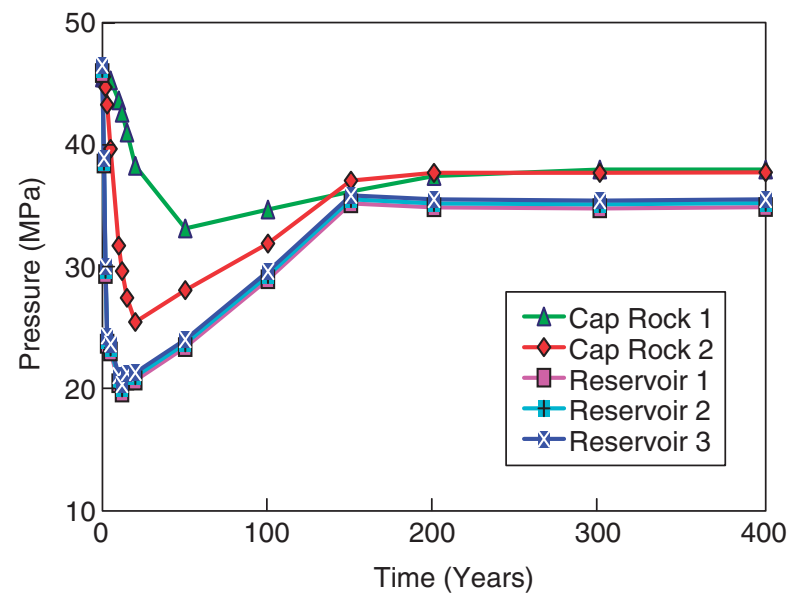

Figure 5

Evolution with time of pressure in reservoir and cap rock for cells crossed by well I 21 . decrease of the cells located in the two cap rock layers is due not only to the pressure decrease in the reservoir but also to the cooling of these cells that leads to additional pressure decrease.

The stress simulations show that the effective stress changes in the cap rock is mainly governed by two phenomena that act in opposite manners. On one hand, the pressure decrease in the cap-rock during production tends to increase the compressive effective stress. On the other hand, the reservoir compaction during production leads to cap rock bending downward over the central part of the reservoir (arch effect) and then tends to decrease the vertical compressive stress in the cap rock due to continuity of vertical displacements. Stress variation in the cap-rock combines a local effect (pore pressure variation) and a structural effect (decrease of vertical compressive stress due to reservoir compaction). During abandonment and reservoir re-pressurization, the two phenomena are still opposed: the pressure increase reduces the compressive effective stress whereas the reservoir uncompaction increases the compressive stress in the cap rock. Because large incertitude exists on the pressure changes in the cap rock layers (sensitivity to the layer thickness, effect of the transmissivity between the reservoir and cap rock layers, uncertainty on the cap rock petrophysical properties) the extreme conditions for the plug have been estimated by looking separately at the two phenomena that drive the effective stress changes in the cap rock.

The first extreme condition is achieved by considering that the cap rock is not affected by pressure changes (this is done by considering a null Biot's coefficient of the cap rock in the geomechanical model). Therefore, for that case, the effective stress change during abandonment is only governed by the structural effect associated with the reservoir un-compaction.
This effect leads to an increase of the compressive stress during abandonment as it can be observed on Figure 6 that displays the diagonal components of the effective stress change during production (0-20 years) and abandonment (20-400 years) in the cell crossed by well I 21 and located in the cap rock layer in contact with the reservoir. Shear stress variations are negligible compared to the variation of diagonal components. Note that the convention of rock mechanics is used so that positive stresses are compressive stresses.

The second extreme condition is achieved by assuming that all the pressure change is transmitted to the solid skeleton of the cap rock (this is done by considering that the Biot's coefficient of the cap rock is equal to 1). In that case, the cap rock behaves as the reservoir and the compressive stress decreases during abandonment because of the reservoir repressurization. This can be observed on Figure 7 that displays the diagonal components of the effective stress in the cell crossed by well I21 and located in the cap rock layer in contact with the reservoir. Shear stress variations are negligible compared to variation of diagonal components.

\section{WELL BORE STRESS MODEL FOR ABANDONMENT}

The previous results are based on a large scale analysis of the reservoir and its containment using coarse reservoir and geomechanics cells. For instance, at the scale of the reservoir cell, the well is not explicitly meshed and the difference between bottom hole pressure and reservoir cell pressure is accounted for using a productivity/injectivity index. In the same way, the stress changes obtained with the geomechanical model cannot be directly used to analyze the local behavior of the plugged well as for instance micro-annuli formation. 


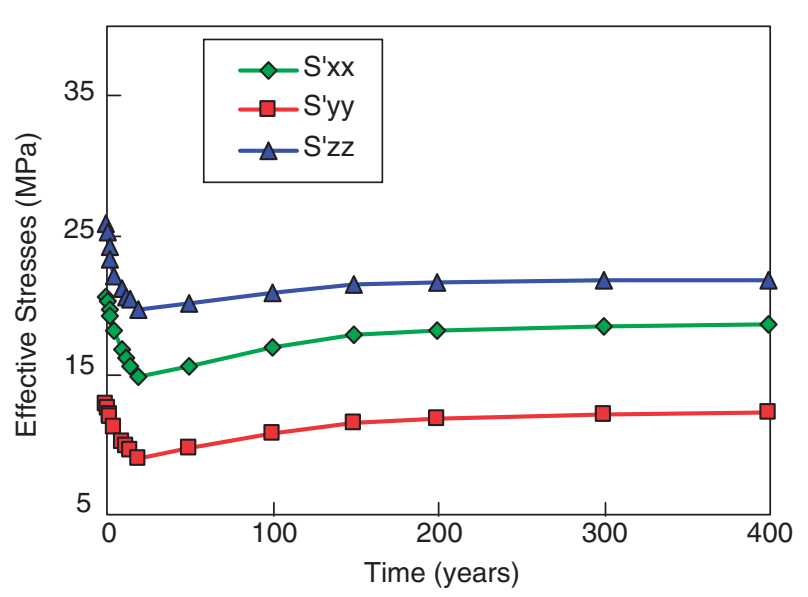

Figure 6

Maximum compressive stress change during abandonment for well I21.

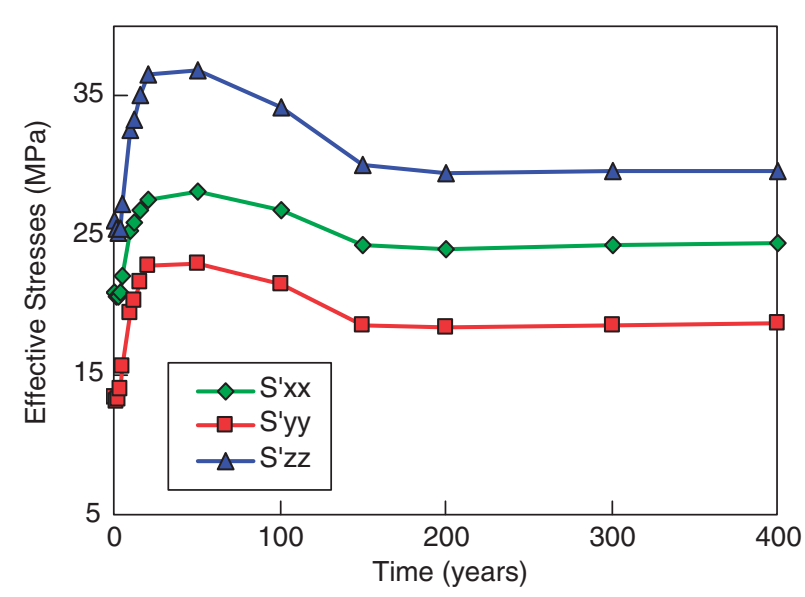

Figure 7

Maximum tensile stress change during abandonment for well I21.
Therefore, the local behavior of the plugged well must be analyzed using a local well bore stress model that explicitly models the bore-hole, the plug plus eventually casing and cemented annulus, and the surrounding rock formation. Actually, in this approach, the thermal changes of the reservoir model and the effective stress changes of the geomechanical model are the input data in the well bore stress model. By using such a model, it becomes possible to compute the effective stress changes in the plug and therefore to analyze the risk of plug failure or of cement/rock de-bonding. In what follows, we present the well bore stress model built for the injector well I21.

The geometry modeled in the well bore stress model is a one-meter thick horizontal section of the cap rock perpendicular to the well axis. This geometry is crossed in its middle by the well bore. The injector well is modeled as an open hole well (no casing nor primary cementing) with a well radius of $10 \mathrm{~cm}$. The well bore model is 10 meters wide in both horizontal directions. In the present case, a lower horizontal extension would have been sufficient, but this lateral extension was required to perform additional analysis such as the influence of heterogeneous distribution of mechanical properties in the horizontal plane. Last, symmetry considerations on loads and geometry allow us to restrict our modeling to one quarter of the well and rock sections in the horizontal direction. Hence, mechanical loading is applied on the lateral, lower and upper boundaries of the well bore model.

Figure 8 sketches a horizontal section of the well bore stress model and Figure 9 displays the mesh used to discretize the plug and the rock in the Finite Element software. The mesh is composed of $27 \times 8 \times 5$ elements: 5 elements along well axis direction and 27 elements along the symmet- ric axes $x$ or $y$ ( 8 elements in the plug and 19 elements in the rock). The remaining 8 elements correspond to the number of rotation in the $x-y$ plane.

The rock material is the shale constituting the cap rock of the reservoir. The shale is modeled as an elastic isotropic material of thermo-elastic properties given in Table 2. The plug is supposed to be made of a conventional cement plug material. This choice of material allows us to assess the risk of plug failure for the most encountered material used for

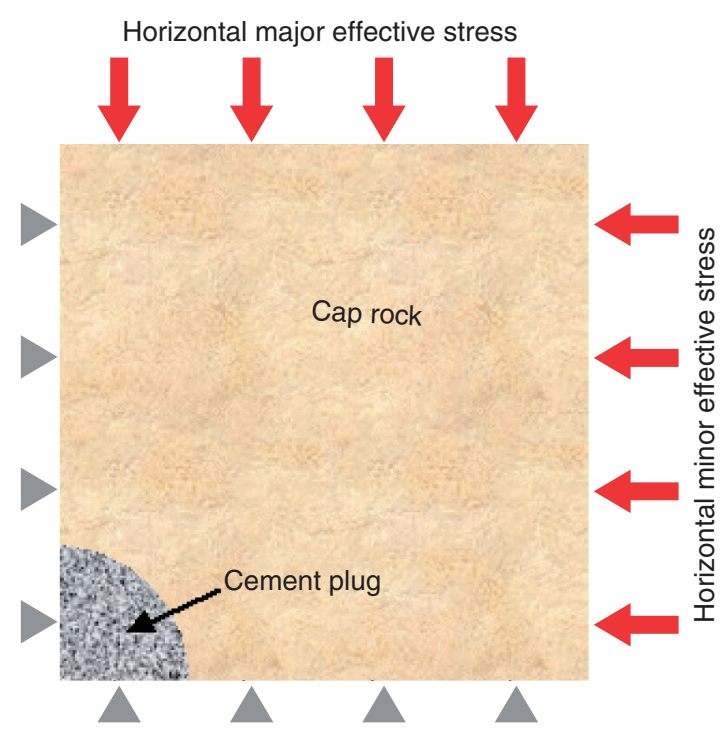

Figure 8

Sketch of the horizontal boundary conditions and loads in the well bore stress model for injector well I21. 


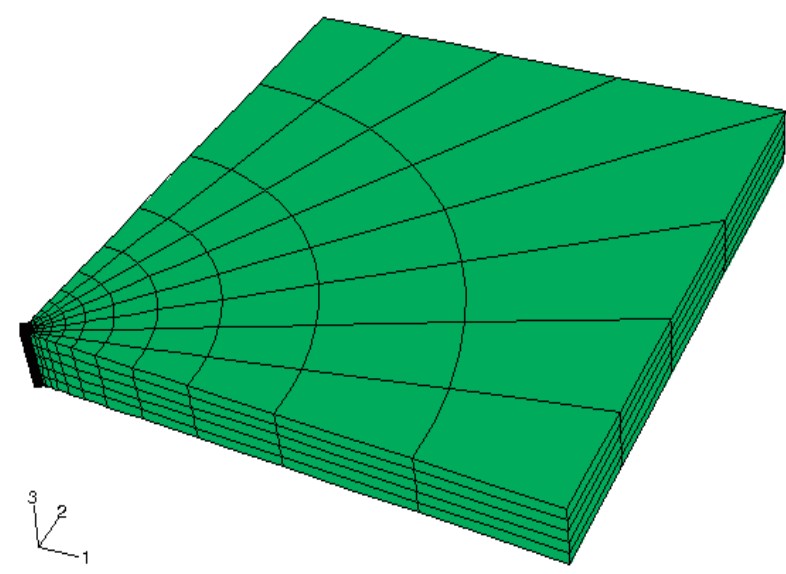

Figure 9

Well bore mechanical domain and mesh for injector well I21.

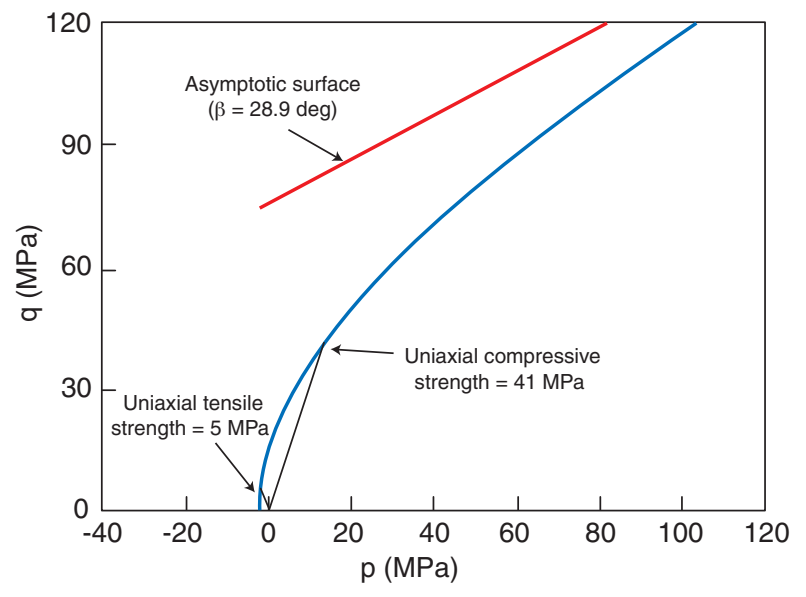

Figure 10

Hyperbolic yield criterion for the standard class G cement of Philippacopoulos and Berndt (2001). well abandonment. The cement material properties are taken from Philippacopoulos and Berndt (2001) who characterized from a mechanical point of view several plain and fiber reinforced well cements used for geothermal wells. The cement considered as a reference material in the well bore stress model is a standard class $\mathrm{G}$ cement with $40 \%$ silica flour mix. Table 2 gives the thermo-elastic properties of the cement: elastic properties (Young's modulus and Poisson's ratio) are determined at $200^{\circ} \mathrm{C}$ and the thermal expansion coefficient is chosen equal to the one of the rock. The last section of the paper presents sensitivity tests with respect to this last parameter.

TABLE 2

Shale and cement thermo-elastic properties

\begin{tabular}{c|c|c}
\hline Material & Shale & Cement \\
\hline $\mathrm{E}(\mathrm{GPa})$ & 10 & 10 \\
\hline$v(-)$ & 0.3 & 0.18 \\
\hline$\alpha\left({ }^{\circ} \mathrm{C}^{-1}\right)$ & $1.6 \cdot 10^{-5}$ & $1.6 \cdot 10^{-5}$ \\
\hline
\end{tabular}

A cement failure surface is defined in the well bore model in order to detect the possible cement failure. The constitutive model commonly used for oil well cement combines a "smeared cracking model" for tension with a plasticity model for compression (see e.g. De Borst and Nauta 1985, Bosma et al. 1999). In the following, the cement yield surface is characterized with a Drucker-Prager type criterion that is well suited for frictional materials such as rock, sand and concrete for which the mean stress affects the material yield and failure strengths. Because cements are inherently low tensile strength materials, a tensile cut-off model must be used to account for their specific behavior in tension. For that reason, the cement failure surface is modeled with an hyperbolic yield criterion (see Abaqus Analysis user's manual) that is a continuous combination of a linear Drucker-Prager criterion at high confining stress and the maximum stress condition of Rankine (tensile cut-off). Note that unlike in the "smeared cracking model" that uses damage elasticity to model the material non linear response at low confining stress, the hyperbolic yield criterion models the whole non linear behavior of the material with an elasto-plastic theory. However, because the present analysis focuses on the risk of plug failure, the failure surface is only used to detect the plug failure but not to predict the plastic deformation in the plug. For the same reason, the material hardening is not accounted for in the well bore stress model. The cement failure surface is built using the values of the internal friction angle $=29$ degrees, uniaxial compressive strength $=41 \mathrm{MPa}$ and uniaxial tensile strength $=5 \mathrm{MPa}$ given by Philippacopoulos and Berndt (2001). These last two values have been used to fit the hardening parameter $=94.5 \mathrm{MPa}$ and the hydrostatic tension strength $=1.9 \mathrm{MPa}$ of the hyperbolic yield criterion. Finally, Figure 10 displays the hyperbolic yield criterion used in the well bore stress model.

Several phases arise during the whole life of the well and it is important to take into account the effects of these different phases on the stress rearrangement in the vicinity of the well. This is done in the well bore stress model by considering several steps in the modeling as displayed on Figure 11. Step 1 provides the initial configuration of the well bore stress model. This configuration models the mechanical equilibrium of rock drilled with a circular open hole and subjected to the initial stress tensor (before reservoir production). 
Step 2 applies the thermal and effective stress changes resulting from the 20 years of reservoir production. The thermal changes given by the reservoir history in the second cap rock layers (see Fig. 4) are homogeneously applied to the rock. Simultaneously, the maximum effective stress changes (see Fig. 6 or 7) computed with the stress simulator during production (0-20 years) are applied over the rock boundaries. The horizontal major and minor effective stress changes are applied to the lateral sides, respectively, of the rock section (see Fig. 8) whereas the vertical effective stress changes are applied to the top and bottom rock sections. At the end of step 2, the hole configuration is deformed such as the pennyshape displayed on step 3 . Then step 4 installs the plug in the deformed configuration of step 3 assuming that the cement is under no internal effective stress (isotropic total stress equal to pore pressure) after setting (i.e. no shrinkage or expansion after curing and no stress variation during transition between liquid to solid states) and also in its solid state at the end of step 4. Step 5 is the main step of the modeling during which we apply the thermal and effective stress changes resulting from abandonment between 20 years and 400 years. The well bore model is made of the cap rock and the cement plug. The state of stress in the model at the beginning of step 5 is the one at the end of step 3 in the cap rock and an isotropic total stress equal to pore pressure (no effective stress) in the cement plug. The thermal changes given by the reservoir history (see Fig. 4) are homogeneously applied to the rock and the cement plug. Simultaneously, the extreme effective stress changes (see Fig. 6 or 7) computed with the stress simulator during abandonment (20-400 years) are applied as loads over the lateral boundaries of the well bore model. The top and bottom boundaries of the cement plug are modeled as free
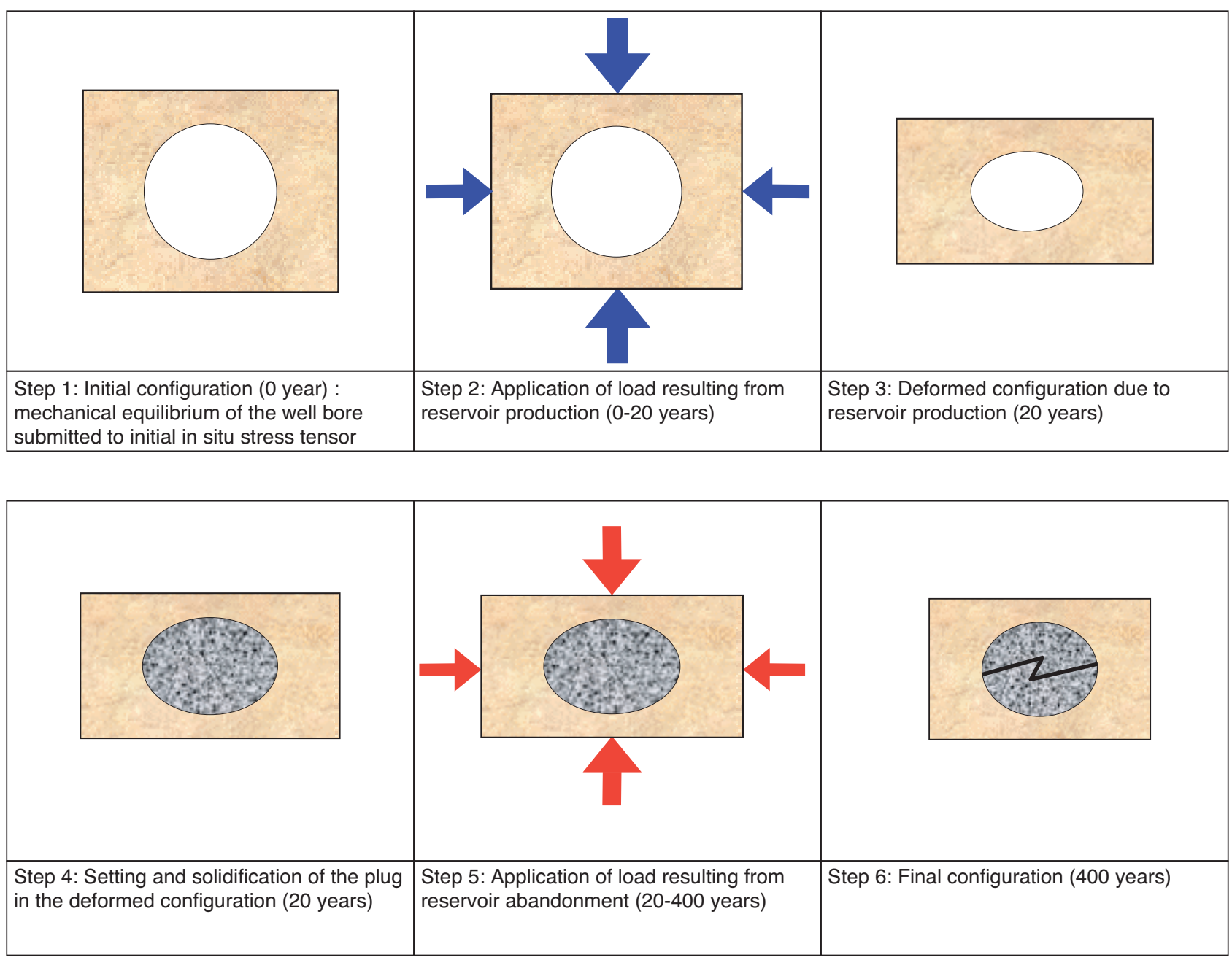

Figure 11

Main steps modeled in the well bore mechanical model. 
boundaries with no total stress change because the bore hole pressure is assumed to remain at the hydrostatic pressure during abandonment. The model also assumes a constant pore pressure in the cement. Step 5 provides stress and strain in the plug during abandonment and can be used to analyze the risk of plug failure during this period as sketched on step 6 .

De-bonding between rock and cement is expected to happen because of their different material properties. Microannulus is particularly critical for the well zonal isolation because it creates a path for formation fluids and renders the well unsafe (see e.g. Ravi et al. 2002). The modeling of the plug-rock de-bonding requires a specific treatment of the interface to prevent from inter-penetration of the plug and the rock. Furthermore, various interaction models can be used to model the behavior of the surfaces when in contact. In what follows, we assume that the plug and the rock remain fully bonded once the plug is sealed. This means that the plug-rock system could be considered as a single continuum material with different mechanical properties for the plug and the rock. This assumption prevents us from a direct observation of possible plug-rock de-bonding with the well bore mechanical model. However the cement/plug debonding can still be predicted by looking at the tensile stresses at the cement-plug interface.

\section{INTEGRITY OF CEMENT PLUG UNDER MAXIMUM LOADS}

This section presents the results of the simulation performed with the well bore stress model built for the injector well I21. The thermal load applied to the rock and the plug is given on Figure 4. The risk of plug failure is analyzed for the maxi- mum effective stress changes highlighted in Section 2. The plug behavior is first analyzed when the rock domain is loaded with the maximum compressive stress change displayed on Figure 6 and second when the rock domain is loaded with the maximum tensile stress change displayed on Figure 7 . In order to analyze the risk of plug failure during abandonment, we display the effective stress changes in the plug in the $\left(p^{\prime}-q\right)$ plane with the hyperbolic yield criterion of the standard class G cement (see Fig. 10). Because it would be difficult to represent stress changes in all the plug, we only present the effective stress changes computed at a Gauss point located in the cement plug, closed to the cement/rock interface and to the top of the plug and closed to the $x=y$ plane. Therefore, in the following, the next plots of the effective stress changes in the plug only display the stress history at the Gauss point previously defined.

\subsection{Case of a Maximum Compressive Load}

The maximum compressive load is obtained with the stress simulator by assuming that the cap rock is not affected by the pressure changes. The resulting stress changes computed with the stress simulator are displayed on Figure 6 and are characterized with a decrease of the compressive stresses during production and an increase of the compressive stress during abandonment. In order to closely look at the load that will affect the well after abandonment, Figure 12 displays the effective stress changes since the beginning of abandonment (i.e. at 20 years). This figure shows that the vertical component (S'zz) increases of about $2 \mathrm{MPa}$ during abandonment whereas in the same time the horizontal components ( $S^{\prime} x x$ and S'yy) increase of 3 to $4 \mathrm{MPa}$. Figure 13 displays the effective stress changes since abandonment in the $\left(p^{\prime}-q\right)$

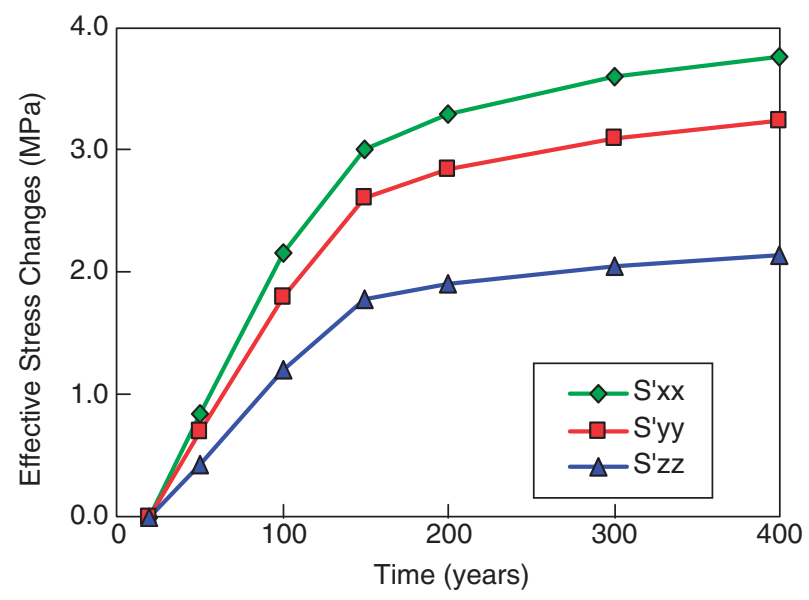

Figure 12

Maximum effective stress increase since the beginning of abandonment.

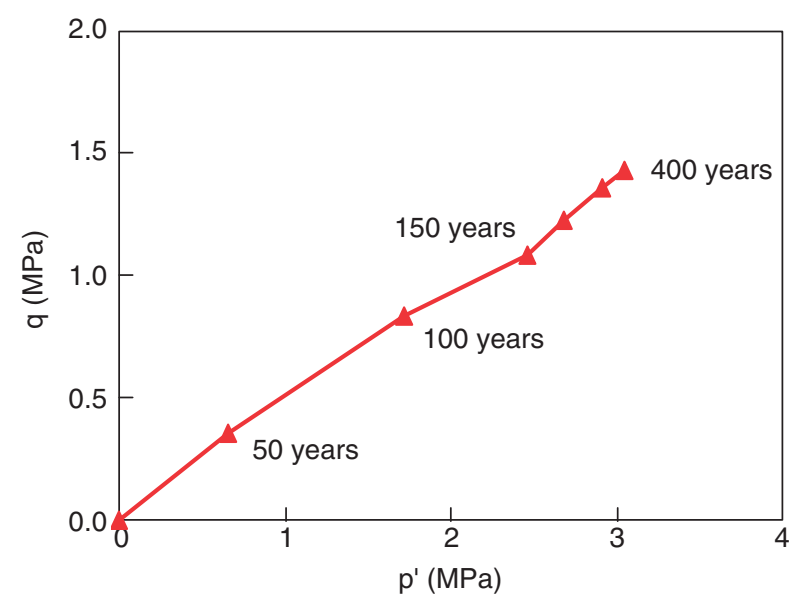

Figure 13

Maximum compressive load in the (p',q) plane. 


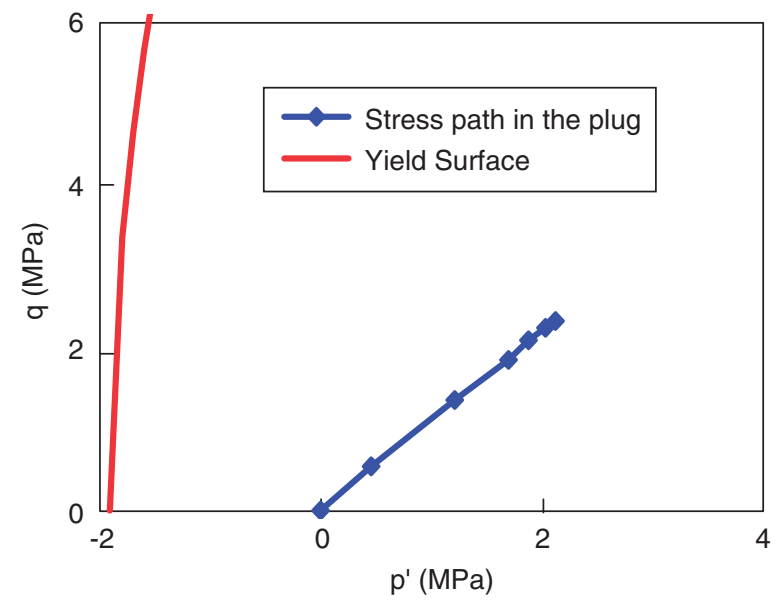

Figure 14

Effective stress path in the plug and comparison with the cement yield surface for the maximum compressive load.

plane: the deviatoric and mean effective (compressive) stresses increase from $0 \mathrm{MPa}$ to 1.5 and $3 \mathrm{MPa}$, respectively.

Figure 14 displays in the $\left(p^{\prime}, q\right)$ plane the stress path in the plug together with the cement yield surface. This stress path has to be compared with the load path displayed on figure 13 . At 400 years, the deviatoric stress computed in the plug is larger than the deviatoric stress applied to the rock whereas the mean stress in the plug is lower than the value applied to the rock. The stress path in the plug is entirely located in the elastic region and the plug stress state at 400 years is far from the failure surface of the cement. As a main conclusion, the maximum compressive load computed for the injector well does not induce a risk of shear failure for a conventional cement plug. This comes from the high compressive strength of conventional cement materials. For the standard class G cement considered here, the deviatoric stress must exceed $14 \mathrm{MPa}$ to induce the cement shear failure. However, the deviatoric stress computed in the plug is far from this value and would require a deviatoric component of the load path of $8 \mathrm{MPa}$ whereas only $1.5 \mathrm{MPa}$ is approximately applied at 400 years (see Fig. 13).

\subsection{Case of a Maximum Tensile Load}

The maximum tensile load during abandonment is obtained when the whole pressure change is transmitted to the solid skeleton of the cap rock. The resulting effective stress changes (see Fig. 7) show an increase of the compressive stresses during production followed with a decrease during abandonment. Figure 15 displays the effective stress changes since the beginning of the abandonment. The compressive stresses slightly increase between 20 years and 50 years because of the warming of the second cap rock layer during the same period of time (see Fig. 4). Actually, the expected decrease of the effective stress due to the re-pressurization of the cap rock between 20 and 50 years (see Fig. 5) is fully compensated with the increase of the effective stress that results from the thermal increase in the cap rock. After 50 years, the thermal effect on the effective stress change is minor compared to the pressure effect so that the effective stress decreases from 50 to 200 years. The effective stress changes since abandonment decrease of about $7 \mathrm{MPa}$ for the vertical component and $4 \mathrm{MPa}$ for the horizontal components. After 200 years, the slight increase of the effective

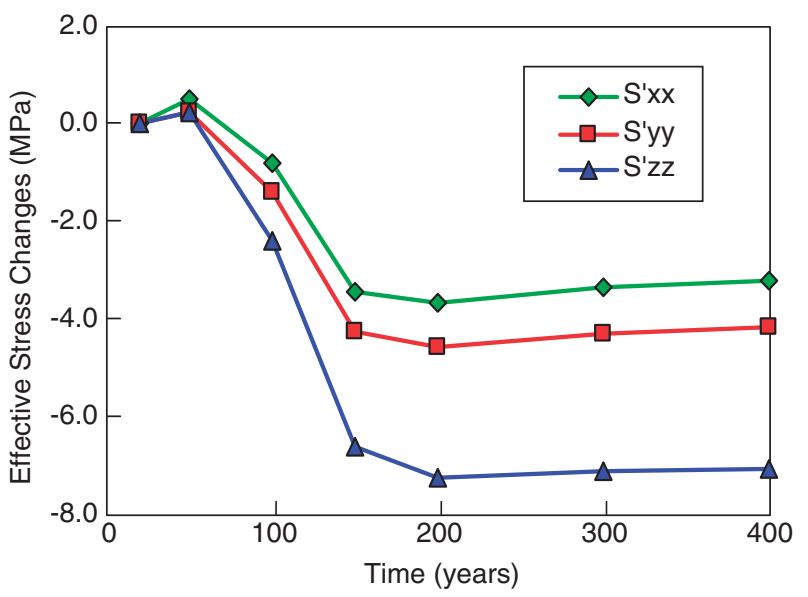

Figure 15

Maximum effective stress decrease since the beginning of abandonment.

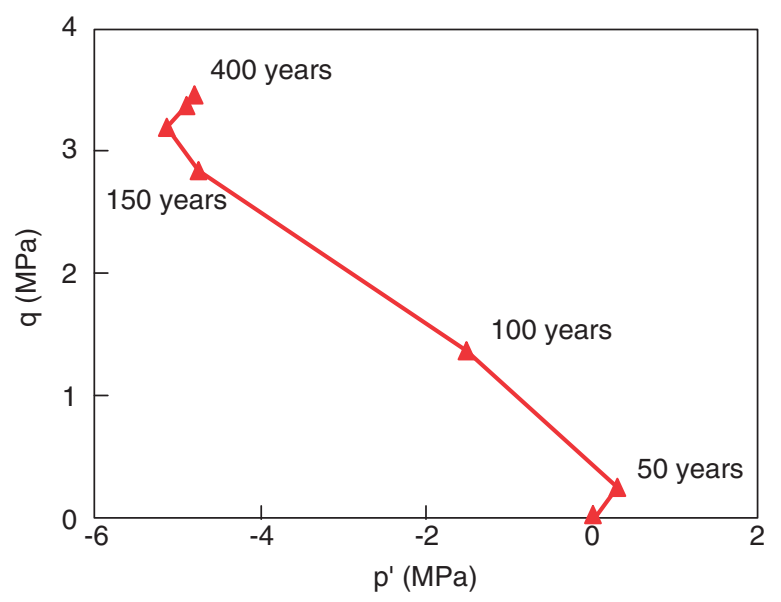

Figure 16

Maximum tensile load in the (p',q) plane. 
stresses results from the slow warming of the cap rock (see Fig. 4) whereas there are no pressure change after 200 years (see Fig. 5). Figure 16 displays the effective stress changes since abandonment in the $\left(p^{\prime}-q\right)$ plane. The load is first characterized with a compressive stress state at 50 years according to the thermal effect. Then, from 50 years to 200 years, the mean effective stress becomes tensile and decreases close to the value of $5 \mathrm{MPa}$. In the same time the deviatoric stress reaches $3 \mathrm{MPa}$. Last, from 200 to 400 years, the thermal effect induces a slight decrease of the mean tensile stress together with a slight increase of the deviatoric stress.

Figure 17 displays in the $\left(p^{\prime}, q\right)$ plane the stress path in the plug together with the cement yield surface. On the contrary to the previous results obtained for a compressive load, the failure surface is reached at 150 years. This means that the plug failed at 150 years because it cannot withstand the decrease of the effective stresses applied at the boundaries of the rock domain. Note that as for the compressive load, at 100 years the deviatoric stress computed in the plug is larger than the deviatoric stress applied to the rock whereas the mean stress in the plug is lower (in absolute value) than the value applied to the rock (see Figs. 16 and 17). Let us also remind that the yield surface displayed on Figure 17 cannot grow because the plastic yielding is not modeled. As a main conclusion, the maximum tensile load computed under the assumption of a cap rock highly sensitive to the pressure changes carries a high risk of tensile failure of a conventional cement plug (or debonding at the interface). This result mainly arises from the null internal effective stress state that exists in the plug after curing. Therefore, a significant decrease of the compressive stress during abandonment directly induces tensile stresses in the plug. Consequently a significant tensile strength of the plug material is necessary to prevent from plug tensile failure. In this case, the cement-based material must be able to withstand a mean tensile stress greater than $2 \mathrm{MPa}$ otherwise it fails. Another way to withstand the tensile load that applies on the plug after abandonment consists in pre-stressing the plug. The pre-stress could be thermally generated by cooling the area of plug installation as analyzed in Bosma et al. (2000) for an elastomeric plug.

\section{SENSITIVITY TESTS ON PLUG PROPERTIES}

The previous work has analyzed the behavior of a conventional cement plug when loaded with the maximum tensile and compressive loads resulting from reservoir abandonment. Especially, it has been shown that conventional cement plug could fail under tension after reservoir abandonment. In order to identify the sealing material properties that will reduce the risk of plug failure after abandonment, this section studies how the plug elastic properties could be adapted to the rock properties and to the thermal and effective stress changes after abandonment. The sensitivity analysis is only

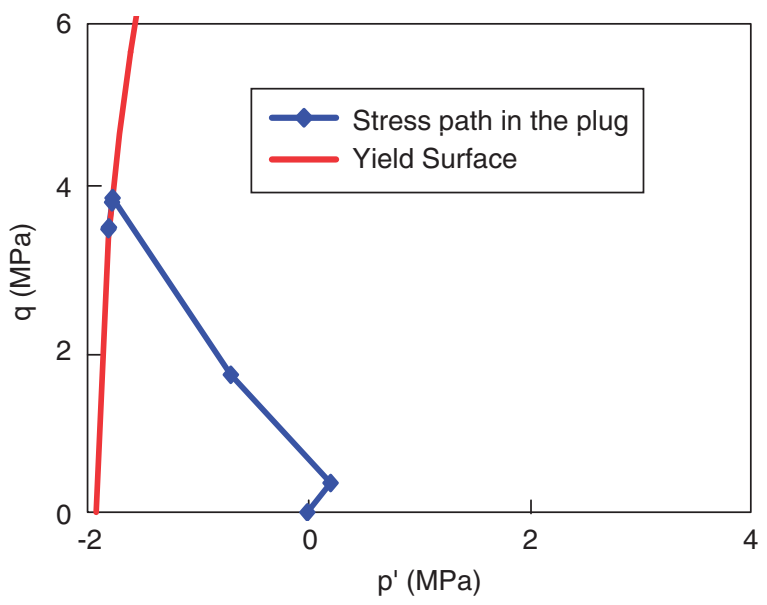

Figure 17

Effective stress path in the plug and comparison with the cement yield surface for the maximum tensile load.

performed for the maximum tensile load for which the risk of plug failure is maximal. The plug elastic properties considered for the sensitivity analysis are the Young's modulus, the Poisson's ratio and the thermal expansion coefficient. The sensitivity analysis performed on this last parameter allows us to analyze the effects of the reservoir thermal changes on the plug stress changes during abandonment. The rock mechanical properties are unchanged with respect to the values defined in Section 3. The thermo-elastic properties used for the standard cement (see Table 2) are used as reference values in the sensitivity analysis. The variation of each of these parameters around its reference value is analyzed independently of the two other parameters, which means that when we analyze the effect of one parameter, the two others remain fixed. The effect of these changes is analyzed on the modification of the stress path in the $\left(p^{\prime}-q\right)$ plane during abandonment at the same Gauss point as defined in Section 3. Furthermore, we assume that the plug failure properties are not modified during the sensitivity analysis and defined as in Section 3 (see Fig. 10). This assumption appears to be not realistic because one may expect that the uniaxial compressive and tensile strengths will change when the elastic properties of cement change. Actually, this assumption is useful to perform the sensitivity analysis without having to change all failure mechanical properties of the plug when each elastic property varies. Therefore, the sensitivity analysis allows us to assess the influence of the plug elastic properties on the plug stress path during abandonment and if the risk of plug failure increases or not. However, we will only detect the failure of standard class $\mathrm{G}$ cement, which will not be always relevant as mentioned previously with respect to the plug elastic properties. 


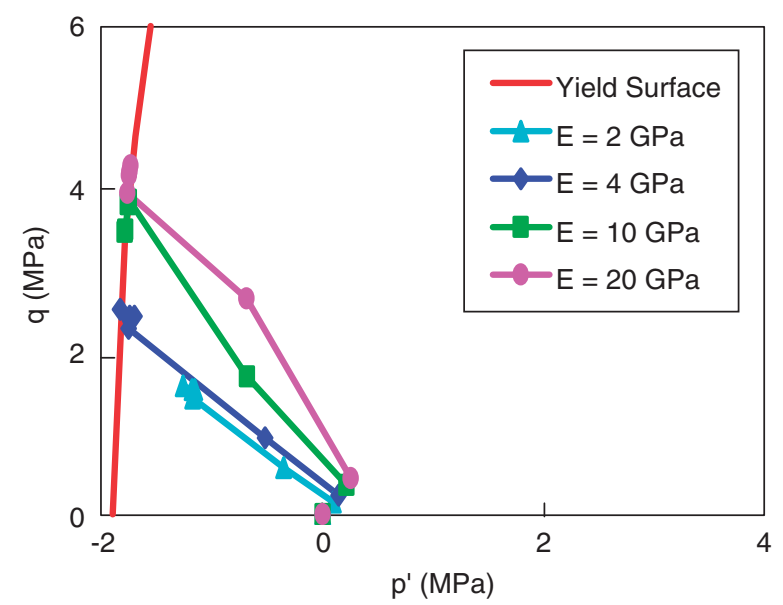

Figure 18

Effect of plug Young's modulus on the effective stress path in the plug.

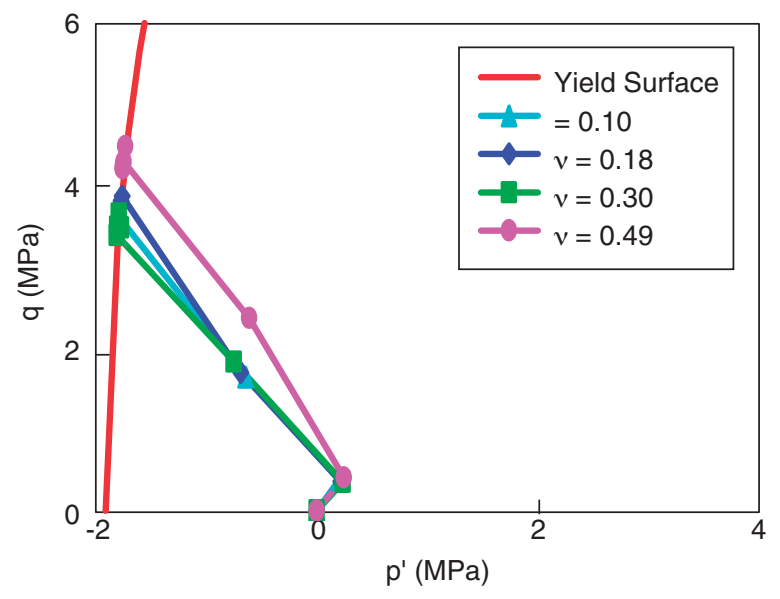

Figure 19

Effect of plug Poisson's ratio on the effective stress path in the plug.

\subsection{Effect of Young's Modulus}

Figure 18 displays, in the $\left(p^{\prime}, q\right)$ plane, the stress path since abandonment in the plug computed with the well bore stress model using different values of the plug Young's modulus (i.e. $2 \mathrm{GPa}, 4 \mathrm{GPa}, 10 \mathrm{GPa}$, and $20 \mathrm{GPa}$ ). The reference value of the plug Young's modulus is $10 \mathrm{GPa}$, for which tensile failure occurs at 150 years. Figure 18 shows that the deviatoric stress in the plug increases with the plug Young's modulus. Therefore, a higher value of the plug Young's modulus raises the risk of plug failure. On the contrary, the risk of failure is reduced for a plug with lower Young's modulus. This is due to the fact that soft sealing material can be more easily deformed so that the mean effective stress is reduced (in absolute value) in the plug. Therefore, sealing materials with low Young's modulus appear to be more suitable for abandonment. Nevertheless, one has to remind that the failure surface used in this sensitivity analysis has not been changed in order to agree with the elastic properties. Then, the difficulty comes from the fact that we must look for a plugging material with low Young's modulus but also, at the same time, with significant tensile strength.

\subsection{Effect of Poisson's Ratio}

Figure 19 displays, in the $\left(p^{\prime}, q\right)$ plane, the stress path since abandonment in the plug computed with the well bore stress model using different values of the Poisson's ratio (i.e. 0.10 , $0.18,0.30$, and 0.49 ). This figure shows that the plug Poisson's ratio does not significantly affect the plug stress path during abandonment. Indeed, the stress path remains unchanged for Poisson's ratio equal to $0.10,0.18$ and 0.30 and only a slight change exists for a high Poisson's ratio (i.e. $v=0.49)$. Actually, additional tests have shown that the effect of the Poisson's ratio is more relevant when the plug is loaded with the maximum compressive load.

\subsection{Effect of Thermal Expansion Coefficient}

Figure 20 displays, in the $\left(p^{\prime}, q\right)$ plane, the stress path since abandonment in the plug computed with the well bore stress model using different values of thermal expansion coefficient (i.e. $1 \cdot 10^{-6 \circ} \mathrm{C}^{-1}, 1.6 \cdot 10^{-5 \circ} \mathrm{C}^{-1}, 3 \cdot 10^{-5 \circ} \mathrm{C}^{-1}$, and $5 \cdot 10^{-5 \circ} \mathrm{C}^{-1}$ ). Let us remind that the rock and plug temperatures increase of approximately $23^{\circ} \mathrm{C}$ between 20 years and 400 years (see

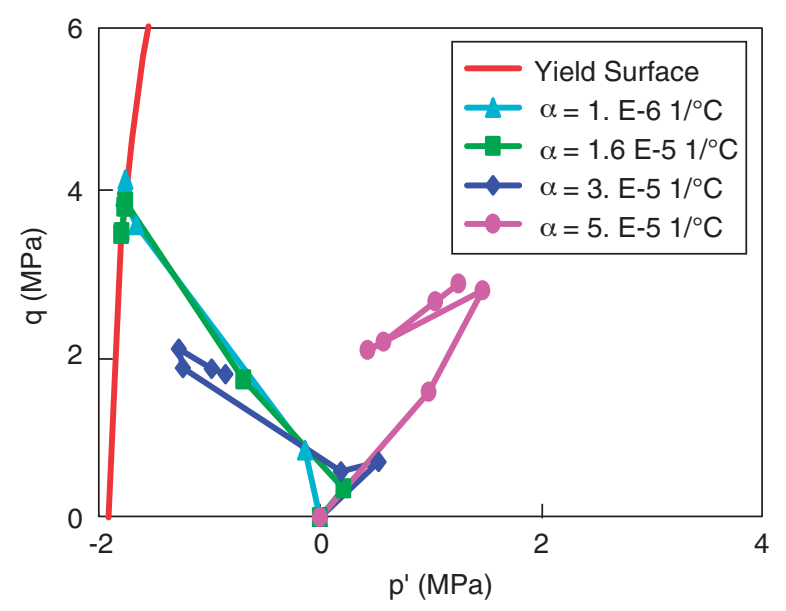

Figure 20

Effect of plug thermal expansion coefficient on the effective stress path in the plug. 
Fig. 4). Figure 20 shows that the thermal expansion coefficient greatly affects the stress paths in the plug:

- For a plug thermal expansion coefficient lower than that of the rock, the risk of plug failure increases because the rock expands more than the plug. Therefore, as the plug/rock interface is supposed to be fully bounded, the rock expansion triggers tensile thermal stresses in the plug. This effect can be observed at 50 years on Figure 20: the stress state is slightly compressive for the plug with the reference thermal expansion coefficient whereas it becomes tensile for the plug with the low thermal expansion coefficient. Therefore, for the case at hand, low thermal expansion coefficients increase the risk of tensile failure in the plug.

- For a plug with higher thermal expansion coefficient than the rock one, the reverse phenomenon takes place. The higher thermal expansion of the plug than the rock one generates compressive thermal stresses in the plug. Therefore the plug tensile failure can be avoided when the plug thermal expansion coefficient reaches about twice the rock thermal expansion coefficient. Furthermore, for a higher thermal expansion coefficient, the thermal stresses in the plug completely cover the extreme load applied at the boundaries of the well bore stress domain so that the plug stress state remains compressive (see Fig. 20).

\section{CONCLUSION}

The sealing materials used for well plugging and abandonment must be adapted to the downhole condition changes that take place after well abandonment. Actually, if the plug wells are located in a field for which pressure, thermal, and stress state are not in equilibrium at the beginning of abandonment, the downhole condition changes during abandonment can lead to plug failure or micro-annulus formation inducing fluid leakage along the well. Therefore this work estimates the pressure, thermal and stress changes after reservoir abandonment for a realistic reservoir field case. The pressure and thermal changes come from a reservoir model that has been extended over a long period of time to analyze the fluid and thermal equilibrium restoration after the end of production. The effective stress changes during production and abandonment result from a geomechanical model that uses the thermal and pressure changes of the reservoir model as loading. A particular attention has been paid to the effective stress change in the cap rock overlaying the reservoir and where critical plugs are installed. It is shown that the effective stress changes in this area are governed either by the pressure increase during abandonment either by the compressive stress increase due to reservoir uncompaction during abandonment. In the first case, the effective stress change since abandonment is characterized by a maximum tensile stress change whereas, in the second case, a maximum compressive stress change is highlighted.
A well bore stress model is built in the second part of the paper to analyze how the pressure, thermal and stress change affect the long term durability of the sealing materials used to plug the well. The well bore stress model explicitly depicts the well geometry and accounts for the stress history before plug setting. The behavior of a conventional class $\mathrm{G}$ cement plug is analyzed when loaded with the thermal and the maximum compressive or tensile effective stress changes coming from the reservoir and geomechanical simulations. Results obtained for the case at hand show that tensile failure occurs when the plug is loaded with the maximum tensile effective stress change whereas no failure happen for the maximum compressive stress change. This is due to the low tensile strength of the cement in contrast with its higher compressive strength that prevents from shear or compressive failures. The sensitivity tests performed at the end of the paper demonstrate that soft sealing materials or initially (thermally) pre-stressed cementitious plugs appear to be more adapted to the downhole condition changes that may occurs after well plugging and abandonment. Further works need to be performed on the well bore stress model to account for the initial stress state that develops in the plug during and after curing. The risk of debonding at the cement/rock interface must also be closely analyzed in future studies because it will largely reduce the plug sealing capacity.

\section{ACKNOWLEDGEMENTS}

This work corresponds to the first phase of the JIP WAOE on Well AbandOnmEnt that begun in January 2003. IFP thanks ConocoPhillips, ENI E\&P Division, Petrobras, Statoil, and Total $E \& P$ for their financial support and for authorizing IFP to publish this work. The authors acknowledge C. Richard De Miranda from Petrobras, P. Brossollet, D. Fourmaintraux, B. Fraboulet and A. Onaisi from Total E\&P, N. Moroni from ENI E\&P Division, N. Nodland from Statoil and E. Steinar from ConocoPhillips for their active participation to this research program.

\section{REFERENCES}

Akgün, H. and Daemen, J.J.K (1999) Design implications of analytical and laboratory studies of permanent abandonment plugs. Can. Geotech.J., 36, 21-38.

Bérest P., Bergues J., Brouard B., Durup J.G. and Guerber B. (2001) A salt-cavern abandonment test. Int. J. Rock Mech. Min., 38, 343-355.

De Borst, R. and Nauta, P. (1985) Non-orthogonal cracks in a smeared finite element model. Eng. Computation., 2, 35-46.

Bosma, M., Cornelissen, E.K. and Schwing, A. (2000) Improved experimental characterisation of cement/rubber zonal isolation materials. Proc. SPE international oil and gas conference and exhibition, Beijing, China, 7-10 November 2000.

Bosma, M., Ravi, K., van Driel, W. and Schreppers, G.J. (1999) Design approach to sealant selection for the life of the well. Proc. 
SPE annual technical conference and exhibition, Houston, Texas, 36 October 1999.

Calvert, D.G. and Smith, D.K. (1994) Issues and techniques of plugging and abandonment of oil and gas wells. Proc. SPE annual technical conference and exhibition, New Orleans, 25-28 September 1994.

Crawshaw, J.P. and Frigaard, I. (1999) Cement Plugs: Stability and Failure by Buoyancy-Driven Mechanism. Paper SPE 56959, Offshore Europe Conference, Aberdeen, Scotland, 7-9 September 1999.

Fourmaintraux, D., Bois, A.-P., Franco, C., Fraboulet, B., and Brossollet, P. (2005) Efficient Wellbore Cement Sheath Design Using the SRC (System Response Curve) Method, paper SPE 94176, SPE Europec/EAGE Annual Conference, Madrid, Spain, 1316 June 2005.

Kelm, C.H. and Fall, R.F. (1999) Well abandonment - A "best practices" approach can reduce environmental risk, Proc. SPE Asia pacific oil and gas conference and exhibition, Jakarta, 20-22 April 1999.
Mainguy, M., Longuemare, P. and Wozniak, J.-M. (2005) Coupled reservoir and geomechanics simulations to assess the risk of well plug failure after reservoir abandonment, Proceedings of the Third Biot Conference on Poromechanics, Norman, Oklahoma, 2005, Edited by: Y.N. Abousleiman, A.H.-D. Cheng, F.-J. Ulm.

Philippacopoulos, A.J. and Berndt, M.L. (2001) Mechanical property issues for geothermal well cements. Geotherm. Resour. Council Trans., 25, 119-124.

Ravi, K., Bosma, M. and Gastebled, O. (2002) Safe and economic gas wells through cement design for life of the well. Proc.SPE gas technology symposium, Calgary, Alberta, Canada, 30 April - 2 May 2002.

Thiercelin, M.J., Dargaud, B., Baret, J.F. and Rodriguez W.J. (1997) Cement design based on cement mechanical response. Proc. SPE annual technical conference and exhibition, San Antonio, Texas, 5-8 October 1997.

Final manuscript received in March 2007 work owned by others than IFP must be honored. Abstracting with credit is permitted. To copy otherwise, to republish, to post on servers, or to redistribute to lists, requires prior specific permission and/or a fee: Request permission from Documentation, Institut français du pétrole, fax. +33147527078 , or revueogst@ifp.fr. 